\title{
DESIGN AND IDENTIFY THE NOVEL PRIMAQUINE DERIVATIVES AS A POTENTIAL CANDIDATE DRUG AGAINST SELECTIVE ANTIBIOTIC-RESISTANT ORGANISMS
}

\author{
K. Kavitha and P. Krishnamoorthy ${ }^{\varpi}$ \\ Department of Chemistry, Dr. Ambedkar Government Arts College, Vyasarpadi-600039, \\ (TamilNadu), India \\ ${ }^{\circledR}$ Corresponding Author: krishthiresearch5@gmail.com
}

\begin{abstract}
In terms of mortality and economic loss, antimicrobial resistance (AMR) continues to be a major public health problem. Several countries' health authorities, including India's, have established containment plans. Multidrugresistant tuberculosis (MDR-TB), methicillin-resistant Staphylococcus aureus (MRSA), and antibiotic-resistant Escherichia coli (AEREC) are all on the rise (R-E. coli),5ICJ, 5M18 and MtGyrA are found important targets for MDR-TB, MRSA and R-E. coli. In this present work 100 novel primaquine derivatives were designed and evaluated their binding affinity in 5ICJ, 5M18 and MtGyrA receptors. ADMET and Toxicity studies were applied to identify the potent PQ-13, PQ-24, PQ-36, PQ-38, PQ-53, PQ-69, PQ-82, PQ-85, PQ-92, PQ-93 derivatives. These derivatives show more binding interactions in MDR-TB, MRSA and R-E. coli receptor and least toxicity effect compared to standards.
\end{abstract}

Keywords: Primaquine, Molecular Docking, MtGyrA Receptor, ADMET, Toxicity Analysis.

RASĀYAN J. Chem., Vol. 14, No.4, 2021

\section{INTRODUCTION}

The crucial public health issue, which can disrupt modern healthcare, is antimicrobial resistance (AMR). ${ }^{1}$ Drug-resistant organism infections could lead to increased death and lengthy hospitalization, which could produce an immense financial strain on the infected people, health services and obstruct the priorities of sustainable development. ${ }^{2}$ The World Health Organization (WHA) implemented the Global Action Plan in 2015 on AMR, which acknowledges the severity of the situation and the danger posed by AMR to health. ${ }^{3}$ After that, several countries formed national action plans themselves (NAPs). A national action Plan to Control AMR was released in April 2017 by the Indian Ministry of Health and Family Welfare. It was presented in May 2017 at WHA 70 in Geneva. This 5-year AMR NAP (2017-2021) lays out India's AMR curbing goals and execution strategies. ${ }^{4}$

AMR itself has more deaths than cancer and road traffic collisions associated with 700,000 people losing battle to combat antimicrobial resistance (AMR) each year and another 10 million people are expected to die of this by $2050 .{ }^{5}$ Economic forecasts indicate that AMR would decrease the GDP by $2-3,5 \%$ by 2050 , with livestock declines of 3-8\%, which cost the world 100 trillion USD. ${ }^{6}$ Economic predictions are expected. A World Health Organization (WHO) and many other stakeholders were aware of the global development of AMR. With AMR as a focus region declared by WHO and other European world leaders who are drawing up their, Action Plans to contain AMR. The sincere attempts against this popular enemy are being made. ${ }^{7}$ India's National Action Plan (NAP) on AMR is also being devised. It is necessary to note that AMR is multiple matters and requires a multi-progress solution to its containment. The One Health principle underlines the interconnections between human health, animal health, food and the environment, and promotes coordination between the health authorities in this fields. ${ }^{8}$

To properly manage AMR, each of these components must be given adequate consideration. Unfortunately, while the focus of most studies was on the unfair use of antimicrobial agents for human and animal welfare, environmental AMR remained widely unnoticed to date. The fact that the environmental contributions of

Rasayan J. Chem., 14(4), 2627-2638(2021)

http://dx.doi.org/10.31788/RJC.2021.1446516

This work is licensed under a CC BY 4.0 license. 


\section{RASĀYAN J. Chem.}

Vol. 14 | No. 4 |2627-2638| October- December | 2021

AMR drivers vary greatly among the geographical regions of the world and therefore figures and recommendations given by any developed nation (for example, England) might not be appropriate for the rest of the world makes this situation more complicated. In April 2017, India recently established a NAP on AMR, listing the efforts proposed for the five years to come. Here, we present the current situation of AMR in India, peculiar problems in this area of the world and drivers of $\mathrm{AMR}^{9,10}$ for the climate.

The future Primaquine products of multidrug-resistant tuberculosis (MDR-TB), methicillin-resistant Staphylococcus aureus (MRSA) and Antibiotic-resistant Escherichia coli (R-E. coli) inhibitors to resolve AMR problems worldwide are anticipated in this study.

\section{Materials and Methods}

\section{EXPERIMENTAL}

In this study, we used BIOVIA Discovery Studio (DS) 2017 software -Trial Version to conduct in silico molecular docking investigations.

\section{Preparation of Protein}

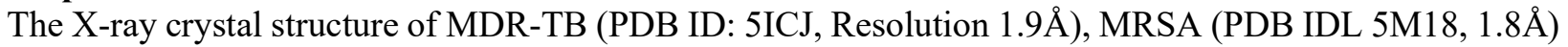
and homology modeled R-E. coli (MtGyrA, $2.0 \AA$ ) were retrieved from RCSB Protein Data Bank (http:// www.rcsb.org/pdb) and previously reported literature. The Forcefield algorithm was used to add hydrogens to the proteins. The energy of protein was then reduced using the CHARM forcefield.

\section{Ligand Design and Preparation}

Initially, 100 novels PQ- derivatives were designed based on the synthetic possibility in microwave method were drawn in ChemDraw software, then energy was minimized and changed in mol (molecule) file format for further docking studies. Also, Primaquine, Amoxicillin, Cefixime and Ciprofloxacin were used as standard drugs for comparisons study.

\section{Docking Studies}

Molecular docking analysis was carried out to determine the most preferred protein-ligand complex geometry. The CDOCKER (CHARMm-based DOCKER) protocol included in DS was used to investigate possible binding modes between the ligands and the target proteins. The parameter that was used to run the CDOCKER was previously defined. The algorithm uses CHARMm force fields and allows for maximum ligand flexibility. We followed previously reported same parameters for this docking studies. ${ }^{11} \mathrm{~A}$ higher binding affinity of the ligands with the target protein is indicated by a higher negative value energy. ${ }^{12}$

\section{ADMET and Toxicity Analysis}

The properties of absorption, distribution, metabolism, elimination and toxicity (ADMET) were predicted in Discovery Studio using ADMET descriptors. The ADMET algorithm was used to determine the various pharmacokinetic parameters of each drug, including hepatotoxicity levels, aqueous solubility, cytochrome CYP2D6 inhibition, blood-brain barrier penetration (BBB), plasma protein binding (PPB), and human intestinal absorption (HIA). These were regarded as drug-likeness descriptors. ${ }^{13-15}$

\section{RESULTS AND DISCUSSION}

Molecular docking is used to predict how one molecule will fit into a receptor and to assess its interaction based on conformation and electrostatic characteristics. ${ }^{16,17}$ Figure-1 shows the secondary structure of the MDR-TB, MRSA and R-E. coli receptor with active site sphere (sphere-molecules binding area). The obtained-CDOCKER binding energy of all three receptors results are described in Fig.-2. From the docking results of the designed 100 PQ derivatives, 50 designed compounds were selected based on their good binding affinity in MDR-TB (5ICJ), MRSA (5M18) and R-E. coli (MtGyrA) compared to the standard Primaquine, Amoxicillin, Cefixime and Ciprofloxacin drugs for further ADMET and Toxicity virtual screening analysis. 

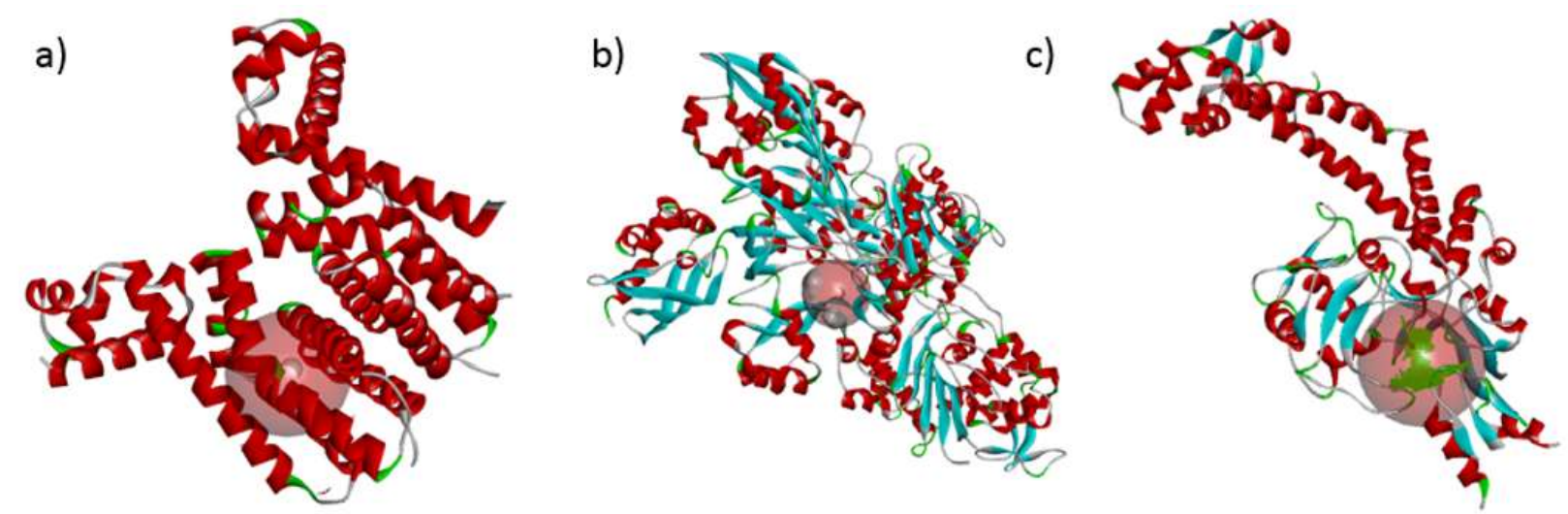

Fig.-1: Secondary Structure of the (a) MDR-TB, (b) MRSA and (c) R-E. coli Receptor with Active Site Sphere

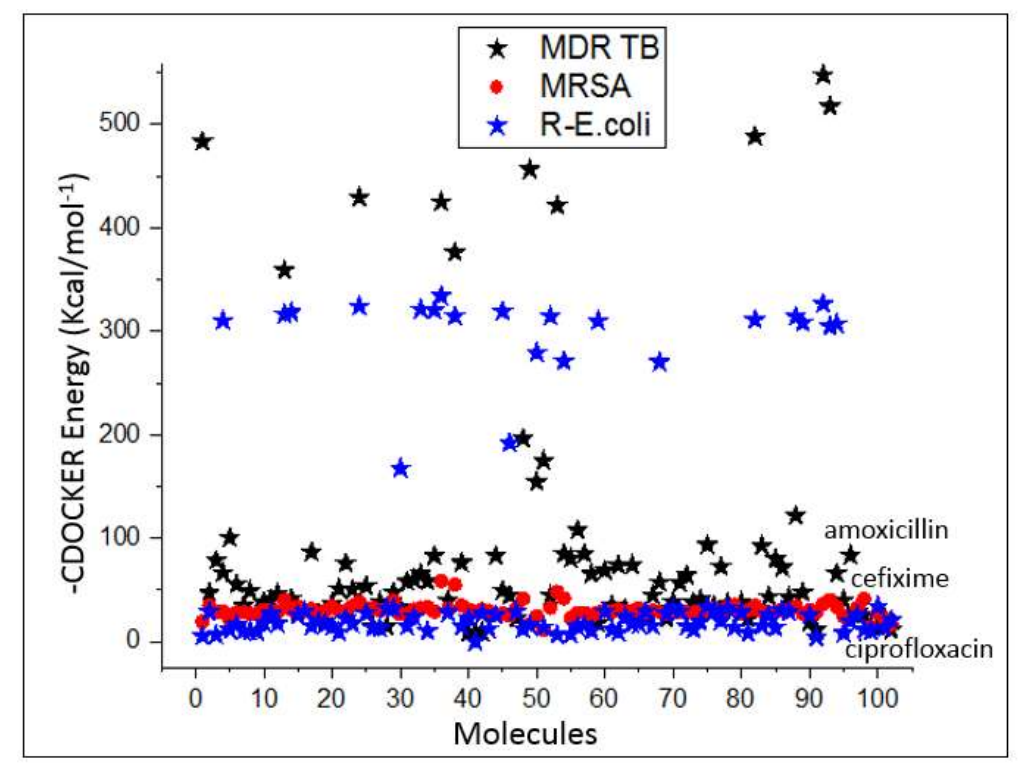

Fig.-2: The Molecular Docking Energy of MDR-TB, MRSA and R-E. coli with PQ-Derivative Compounds

\section{Molecular Docking Analysis of MDR-TB}

From the selected 50 hit PQ derivatives, the molecular PQ-92 shows higher binding CDOCKER Energy ($547.82 \mathrm{Kcal} / \mathrm{mol}-1)$ in MDR-TB receptor compared to standard Amoxicillin $(-11.211 \mathrm{Kcal} / \mathrm{mol}-1)$. This molecule formed more non-bonded interaction with active site amino acids (Fig.-3). Mainly, the alkyl chain of PQ-92 interacted with respective amino acids by Alkyl/van der Waals interactions and aromatic benzene groups forms Pi-alkyl interaction in the active site. Subsequently, the PQ- 93 shows non-bonded interaction by the hydrophobic groups with active site residues (Fig.-4). The binding energy of PQ-93 is -517.44 $\mathrm{Kcal} / \mathrm{mol}-1$. The pentyloxy group of PQ-93 interacted with alkyl group side chain of Leu residues by Alkyl interactions. Additionally, the benzyloxy groups form Pi-sulphur interaction with Met 74 and Met 137 Sulphur side chains.

In this insilico study, the Primaquine drug is a basic nucleus of our designed molecules. So that the Primaquine is used to compare the binding affinity in all the receptors. The molecular docking of Primaquine in MTR-TB, shows fifteen to twenty-fold lower binding energy $(-22.8515 \mathrm{Kcal} / \mathrm{mol}-1)$ than screened fifty PQ-derivatives. The primary amine group of Primaquine forms strong Hydrogen bond interaction with Thr 138 residue with a $1.9 \AA$ bond distance. Similarly, the amide group forms a Hydrogen bond (1.8 $\AA$ ) with Asp 168 residing (Fig.-5). In the current work, the Amoxicillin drug was used to analyze the binding energy in the MDR-TB receptor (Fig.-6). The molecular docking energy of Amoxicillin in MDR-TB is $-11.2113 \mathrm{Kcal} / \mathrm{mol}-1$. This drug shows three Hydrogen bond interactions with $1.8 \AA$, $2.0 \AA$, 


\section{RASĀYAN J. Chem.}

Vol. 14 | No. 4 |2627-2638| October-December | 2021

$1.7 \AA$ bond distance respectively. But this drug forms only a few non-bonded interactions with MDR-TB. So that, its shows very low binding interaction with active site residues. Overall, this binding energy is very low when compared to other PQ-derivatives.

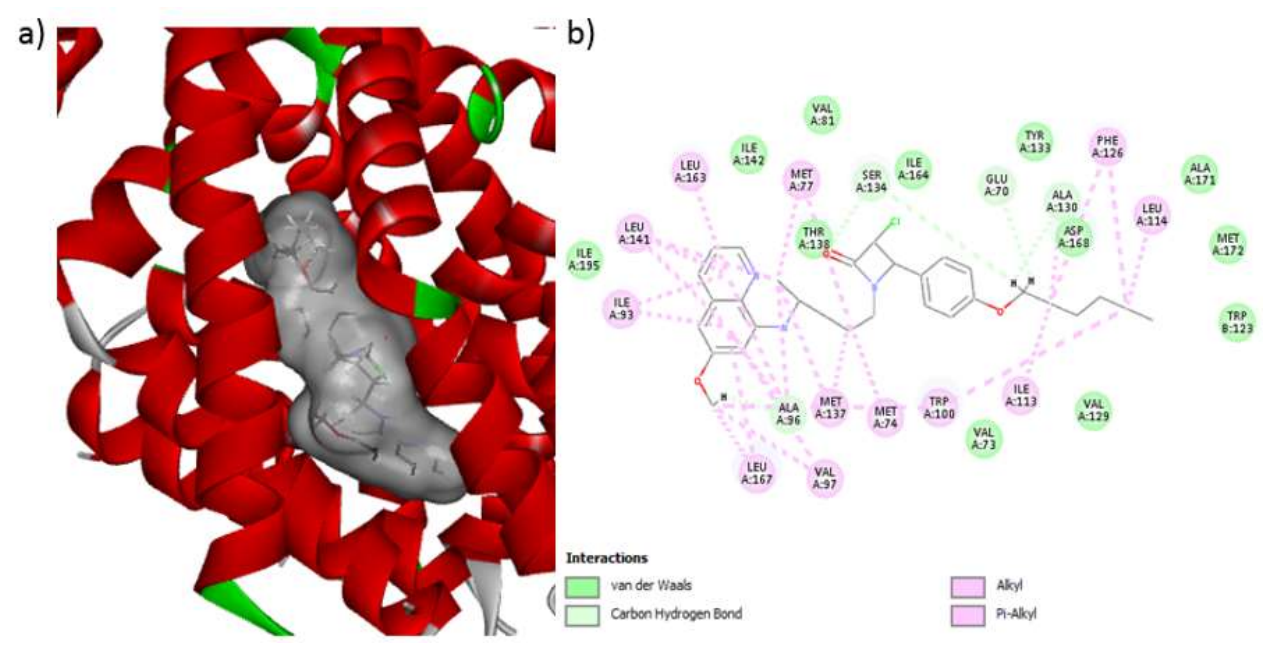

Fig.-3: (a) 3D and (b) 2D binding interaction of PQ-92 Derivatives with the Active Site of the MDR-TB Receptor

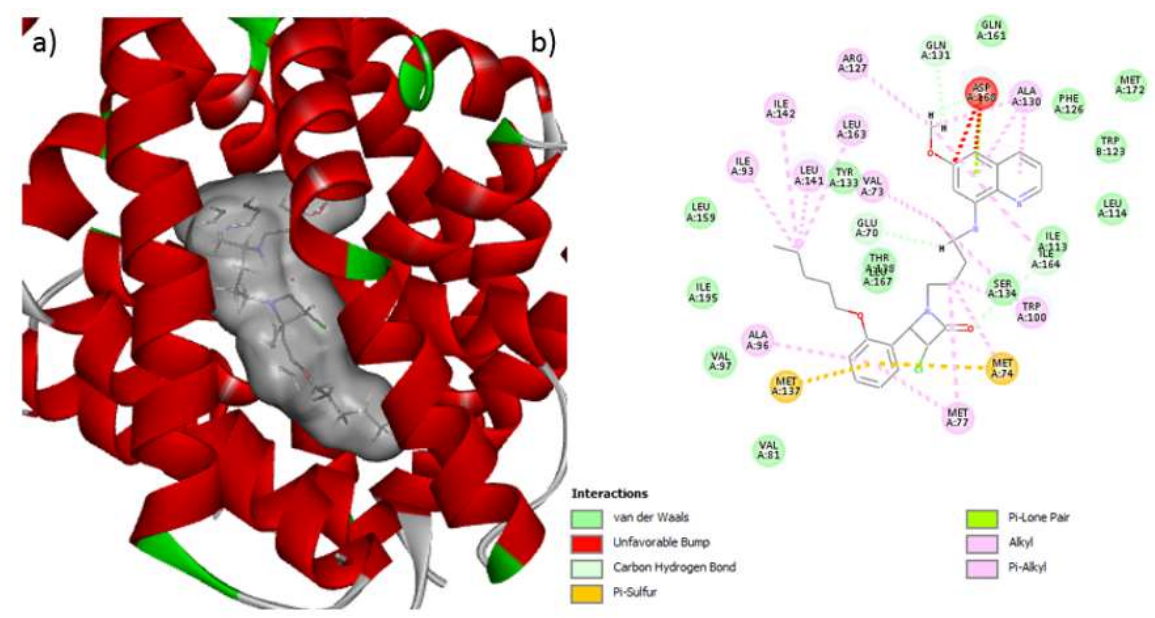

Fig.-4: (a) 3D and (b) 2D binding interaction of PQ-93 Derivatives with the Active Site of the MDR-TB Receptor

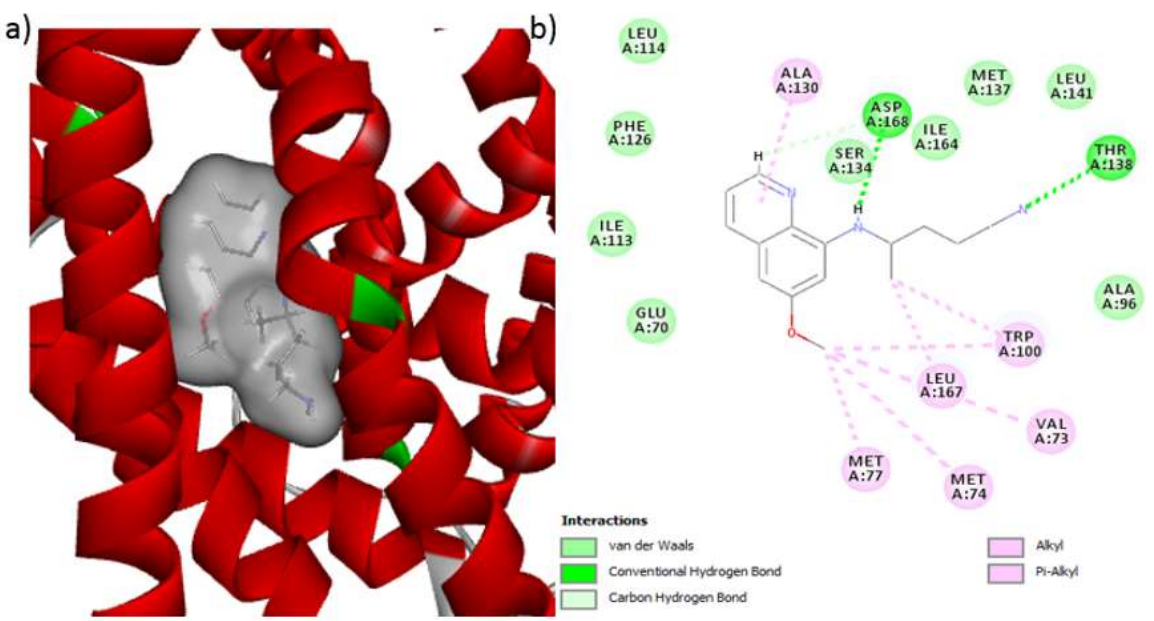

Fig.-5: (a) 3D and (b) 2D binding interaction of Primaquine with the Active Site of MDR-TB Receptor 


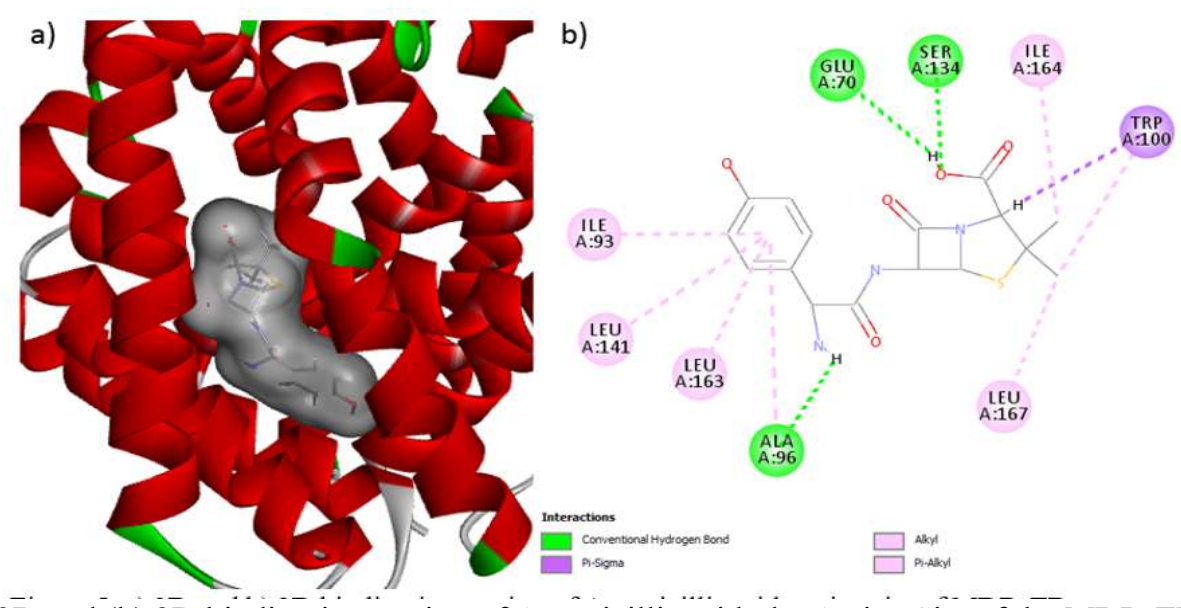

Fig.-6: (a) 3D and (b) 2D binding interaction of Amoxicillin with the Active Site of the MDR-TB Receptor

\section{Molecular Docking Analysis of MRSA}

In this molecular docking analysis on MRSA receptor, the molecular PQ-36 shows higher binding affinity (-CDOCKER Energy is $58.519 \mathrm{Kcal} / \mathrm{mol}^{-1}$ ) compared to other PQ derivatives, Primaquine and Cefixime standard drug. Cefixime is currently resisted by MRSA. The PQ-36 derivatives interacted with active site residues by two hydrogen bond interactions, one Pi-Sulphur, five Alkyl/ Pi-Alkyl, and one Pi-Sigma interaction (Fig.-7). The lone pair electrons in the benzyloxy group form one strong Hydrogen bond interaction with Lys 148 residue. Similarly, the $\mathrm{C}=\mathrm{O}$ group of the thiazolidinedione interacted with Arg241 by hydrogen bond $(1.8 \AA)$. Moreover, the benzyloxy group shows Pi-Sigma interaction with Lys 148 residue. Here, the $6 \mathrm{Pi}$ - electrons of the benzyloxy group interacted with sigma electrons of the Lys residue. Also, the Met 372 residue in the MRSA receptor, forms Sulphur-X interaction with-OCH${ }_{3}$ group.

Further, the PQ-38 shows van der Waals, Pi-Sulphur, Alkyl, and Pi-Alkyl interaction with MRSA receptors. The CDOOCKER energy of these molecules is $-55.0631 \mathrm{Kcal} / \mathrm{mol}^{-1}$. The Side OH group of the Ser 240 residue forms one strong Hydrogen bond with the -NH amide group of the PQ-38. Similarly, 2-Ethyloxy of this derivative has shown one Hydrogen bond with Lys 148 residue. Apart from these binding interactions, most of the active residues in MRSA receptors, involved by van der Waals interaction and increase the binding energy compared to standard drugs(Fig.-8). Mainly, the Primaquine binding energy in MRSA is $-22.528 \mathrm{Kcal} / \mathrm{mol}^{-1}$. The primary amine in Primaquine shows two hydrogen bond interactions with Thr 165 and Arg 151 residues (Fig.-9). But this drug forms only a few bonded and non-bonded interactions in MRSA receptors. The standard Cefixime drug interacted in MRSA receptor by four hydrogen bonds, one Pi-Sulphur, and multiple van der Waals, Alkyl/Pi-alkyl interactions with -16.4637 $\mathrm{Kcal} / \mathrm{mol}^{-1}$.CDOCKER energy (Fig.-10). The Arg 241 residue forms two hydrogen bonds with $-\mathrm{C}=\mathrm{O}$ group of the Cefixime and His 293 forms Pi-Sulphur interaction with 5 membered ring molecules.

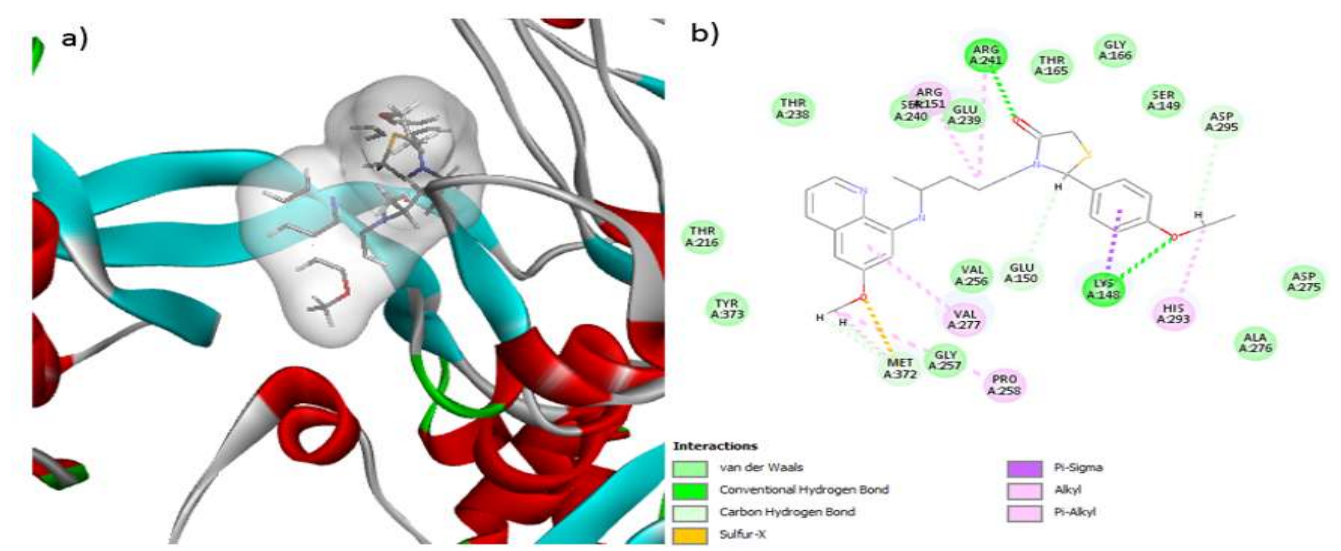

Fig.-7: (a) 3D and (b) 2D binding interaction of PQ-36 Derivatives with the Active Site of MRSA Receptor 
RASĀYAN J. Chem.

Vol. 14 | No. 4 |2627-2638| October- December | 2021

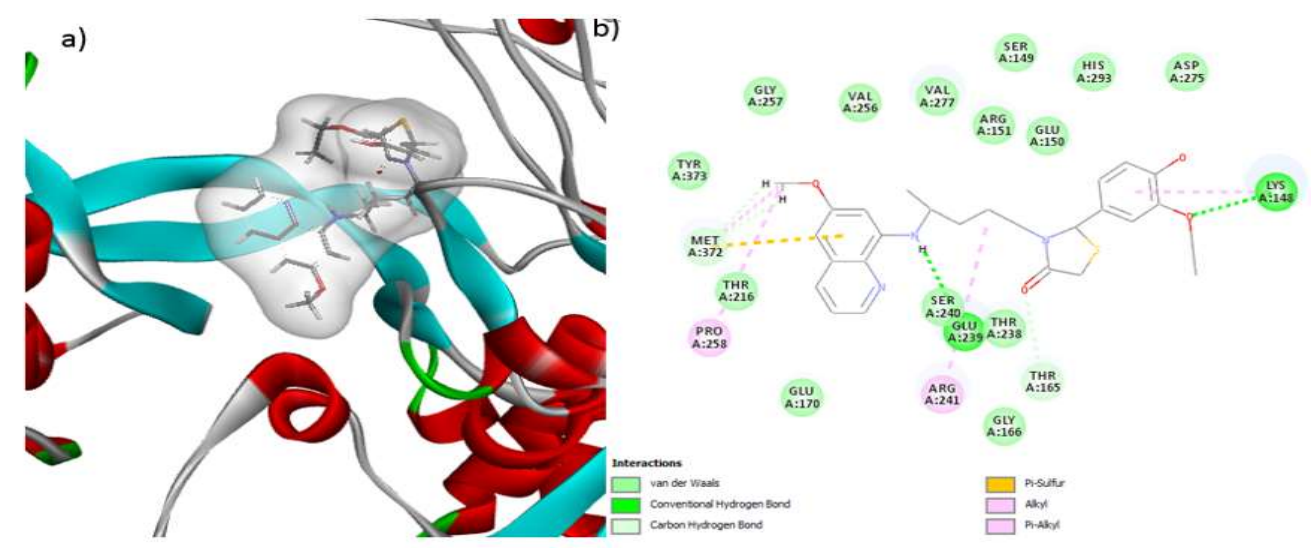

Fig.-8: (a) 3D and (b) 2D binding interaction of PQ-38 Derivatives with the Active Site of MRSA Receptor

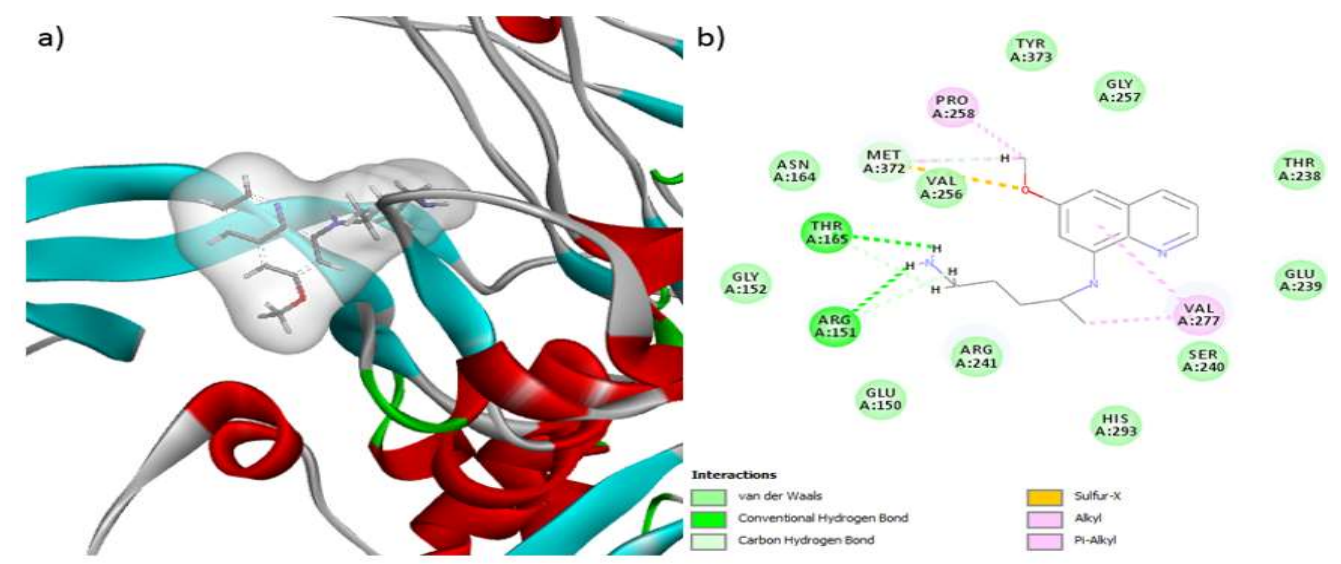

Fig.-9: (a) 3D and (b) 2D binding interaction of Primaquine with the Active Site of MRSA Receptor

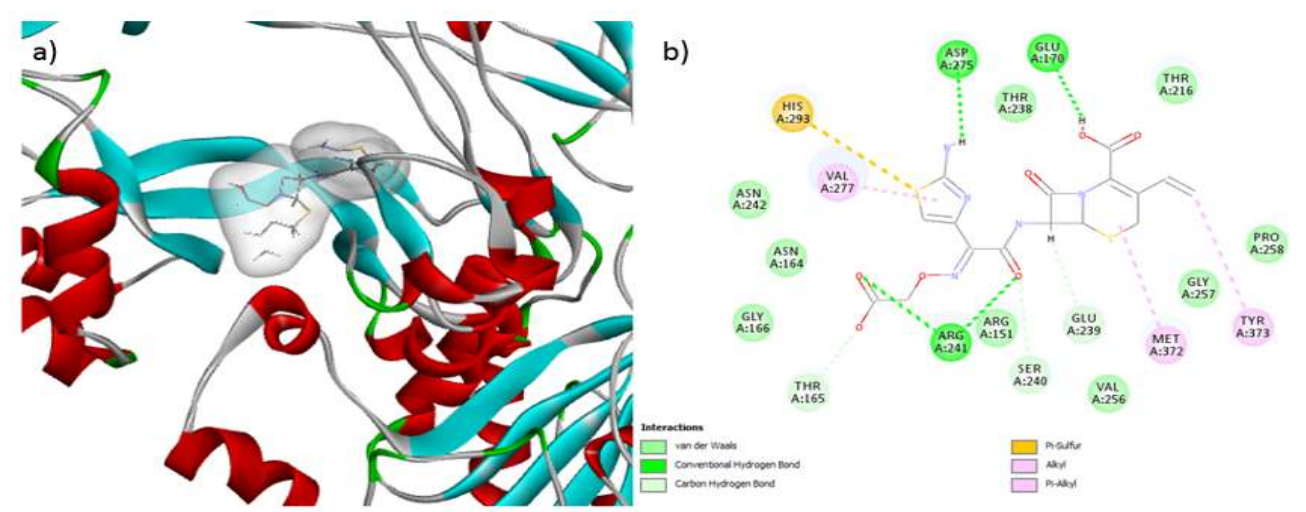

Fig.-10: (a) 3D and (b) 2D binding interaction of Cefixime with the Active Site of MRSA Receptor

\section{Molecular Docking Analysis of R-E. coli}

The molecular docking on R-E. coli, the molecule PQ- 24 shows higher binding energy compared to other PQ derivatives and standard Primaquine, Ciprofloxacin drug. The -CDCOKER energy of PQ-24 in R-E. coli is $324.2 \mathrm{Kcal} / \mathrm{mol}^{-1}$. It is shown, the thiazolidine, ring forms, Hydrogen bond with the side chain -OH of the Ser 97 residue. Similarly, Gln 267 residue forms one hydrogen bond with the pyridine group of the PQ-24 derivatives. Phe 96 residue formed one Pi-Sulphur interaction with thiazolidine ring, Sulphur atom (Fig.-11). The molecule PQ-23 shows $-316.49 \mathrm{Kcal} / \mathrm{mol}^{-1}$ CDOCKER binding energy in R-E. coli receptor (Fig.-12). There is no hydrogen bond involved in this binding, but the van der Waals, Alkyl/ Pi-alkyl and $\mathrm{Pi}-\mathrm{Pi}$ stacked interactions involved to increase the binding energy compared to Primaquine (-20.8913 $\left.\mathrm{Kcal} / \mathrm{mol}^{-1}\right)$, Ciprofloxacin $\left(-13.2166 \mathrm{Kcal} / \mathrm{mol}^{-1}\right)$ drug. 
RASĀYAN J. Chem.

Vol. 14 | No. 4 |2627-2638| October- December | 2021

Figure-13, shows the binding interactions of Primaquine in R-E. coli receptor. The Sigma bond of the Gln 267 residue forms Pi-Sigma interaction with Pi- electrons of the pyridine group of the Primaquine drug. Also, the primary amine has interacted with Arg91 by hydrogen bond interactions. The ciprofloxacin drug shows three hydrogen bonds with Ser 111, Ser 97 and Tyr 266 respectively. Arg 91 residue interacted with the aromatic benzene group of Ciprofloxacin (Fig.-14).

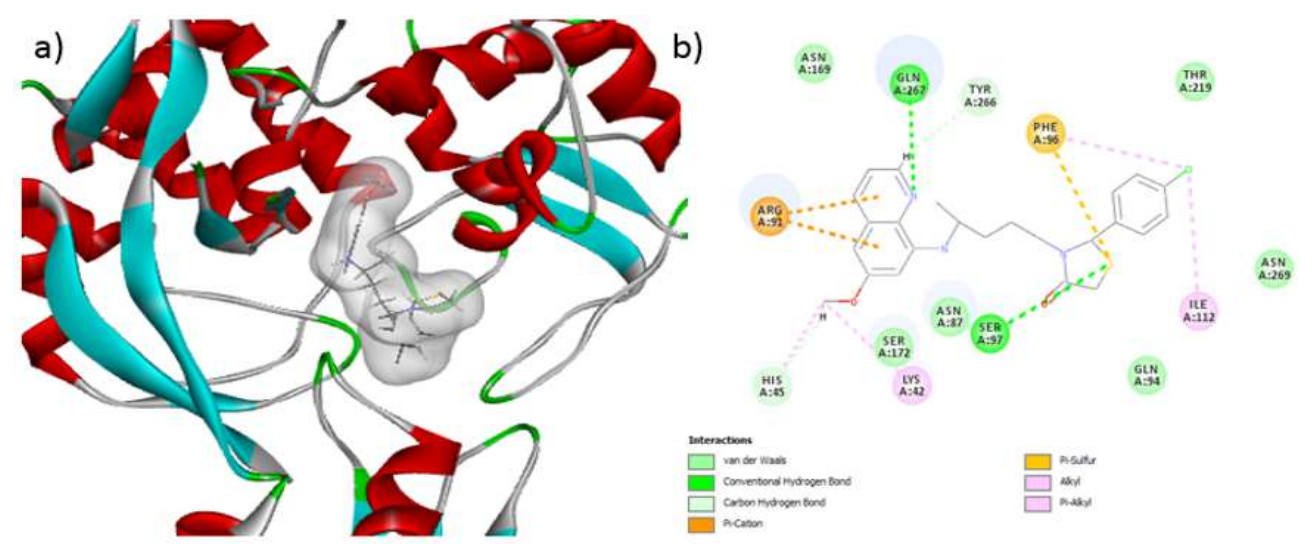

Fig.-11: (a) 3D and (b) 2D binding interaction of PQ-24 with the Active Site of R-E. coli Receptor

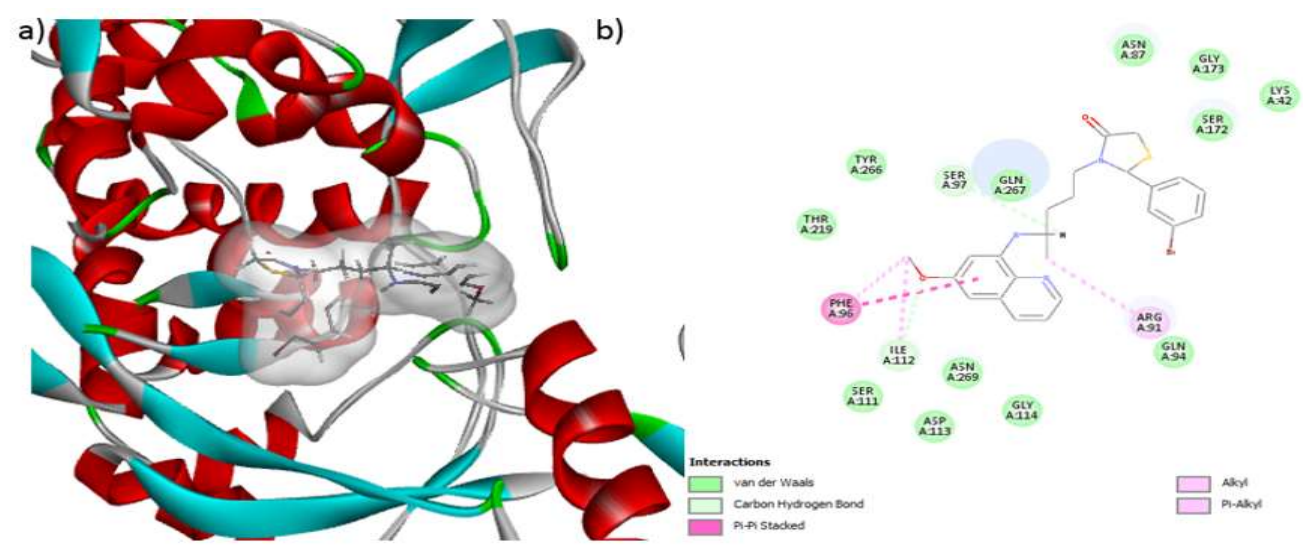

Fig.-12: (a) 3D and (b) 2D binding interaction of PQ-23 with the Active Site of R-E. coli Receptor

\section{ADMET and Toxicity Study}

The in silico ADMET analysis was performed to predict the pharmacokinetic properties (Absorption level, solubility level, Hepatotoxicity, Blood-brain barrier, Cytochrome P450 2D6 inhibitor, Plasma protein binding, logarithm of the partition coefficient between n-octanol and water (AlogB) and Polar surface area) of the screened fifty PQ- derivatives. Also, in silico toxicity parameters calculate the all-toxic values (Table2).

The ADMET result of the screened fifty PQ-derivatives is shown in figure 15. After examining the ADMET and Toxicity study, finally, ten potent (PQ-13, PQ-24, PQ-36, PQ-38, PQ-53, PQ-69, PQ-82, PQ-85, PQ92, PQ-93) hit compounds were screened. The ADMET and Toxicity study of these ten PQ-derivatives is described in Table-1 and Table-2. For the HIA and BBB models, all 10 PQ-derivatives and standard ciprofloxacin fall inside the 95 percent and 99 percent confidence ellipses, respectively. These compounds also demonstrated excellent cell membrane absorption, with PSA 1402 (Polar surface area) and AlogP98 5 meeting the specified parameters. It revealed that the chosen compounds had good BBB, absorption, solubility, hepatotoxicity, CYP2D, PPB levels, positive carcinogenicity, Ames mutagenicity, skin sensitization, ocular irritancy, and aerobic biodegradability. Table-3 lists the chemical structures and properties of the $10 \mathrm{PQ}$ derivatives that were chosen. 
RASĀYAN J. Chem.

Vol. 14 | No. 4 |2627-2638| October- December | 2021

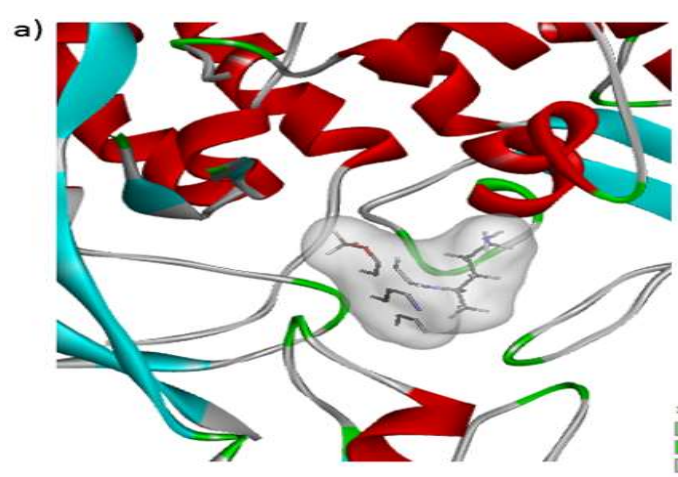

b)

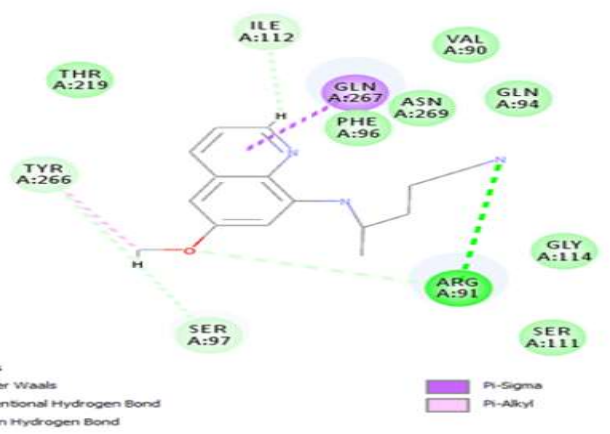

Fig.-13: (a) 3D and (b) 2D binding interaction of Primaquine with the Active Site of R-E. coli Receptor

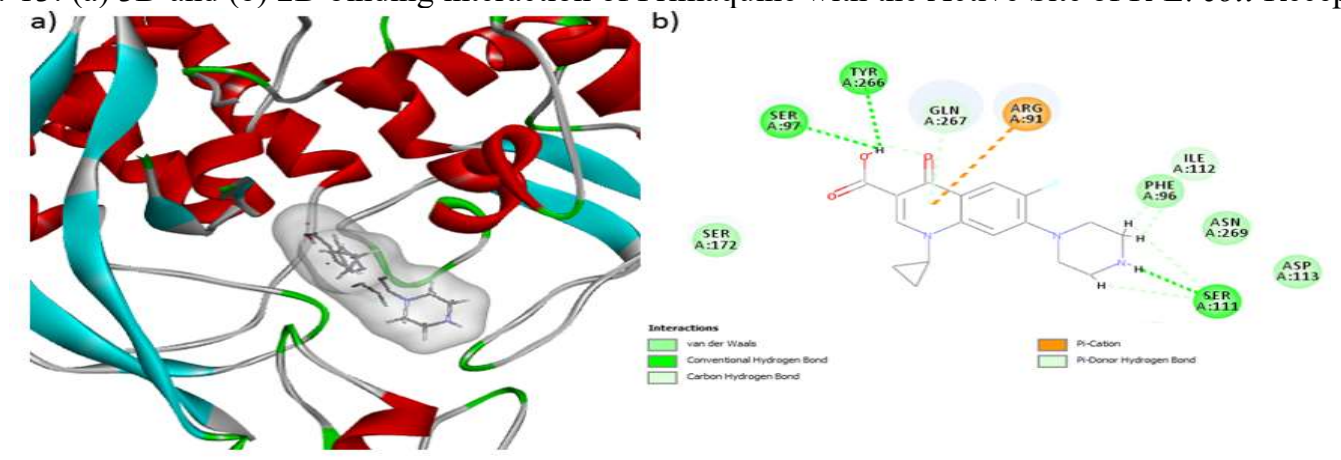

Fig.-14: (a) 3D and (b) 2D binding interaction of Ciprofloxacin with the Active Site of R-E. coli Receptor

Table-1: ADMET Result of Virtually screened 10 designed PQ- Derivatives

\begin{tabular}{c|c|c|c|c|c|c|c|c}
\hline $\begin{array}{c}\text { Molecules } \\
\text { Name }\end{array}$ & $\begin{array}{c}\text { Benetration } \\
\text { Level }\end{array}$ & $\begin{array}{c}\text { Absorption } \\
\text { Level }\end{array}$ & $\begin{array}{c}\text { Solubility } \\
\text { Level }\end{array}$ & $\begin{array}{c}\text { Hepato } \\
\text { toxicity }\end{array}$ & $\begin{array}{c}\text { CYP2D6 } \\
\text { Inhibitor }\end{array}$ & $\begin{array}{c}\text { PPB } \\
\text { Level }\end{array}$ & AlogP98 & $\begin{array}{c}\text { PSA } \\
\text { 2D }\end{array}$ \\
\hline PQ-13 & Very-Low & High & High & No & No & $<90 \%$ & 3.245 & 97.24 \\
\hline PQ-24 & Very-Low & High & High & No & No & $<90 \%$ & 2.247 & 88.34 \\
\hline PQ-36 & Very-Low & High & High & No & No & $<90 \%$ & 4.158 & 99.34 \\
\hline PQ-38 & Very-Low & High & High & No & No & $<90 \%$ & 3.145 & 105.53 \\
\hline PQ-53 & Very-Low & High & High & No & No & $<90 \%$ & 2.981 & 104.25 \\
\hline PQ-69 & Very-Low & High & High & No & No & $<90 \%$ & 3.458 & 98.24 \\
\hline PQ-82 & Very-Low & High & High & No & No & $<90 \%$ & 4.175 & 102.45 \\
\hline PQ-83 & Very-Low & High & High & No & No & $<90 \%$ & 4.913 & 110.26 \\
\hline PQ-92 & Very-Low & High & High & No & No & $<90 \%$ & 4.642 & 99.34 \\
\hline PQ-93 & Very-Low & High & High & No & No & $<90 \%$ & 3.945 & 107.35 \\
\hline
\end{tabular}

Table-2: Probability Values of Different Toxicity Models of the selected 18 Compounds by TOPKAT Analysis

\begin{tabular}{ll|l|l|l|l|l|l|l|l|l|l}
\hline Model & $\begin{array}{l}\text { PQ- } \\
13\end{array}$ & $\begin{array}{l}\text { PQ- } \\
24\end{array}$ & $\begin{array}{l}\text { PQ- } \\
36\end{array}$ & $\begin{array}{l}\text { PQ- } \\
38\end{array}$ & $\begin{array}{l}\text { PQ- } \\
53\end{array}$ & $\begin{array}{l}\text { PQ- } \\
69\end{array}$ & $\begin{array}{l}\text { PQ- } \\
82\end{array}$ & $\begin{array}{l}\text { PQ- } \\
83\end{array}$ & $\begin{array}{l}\text { PQ- } \\
92\end{array}$ & $\begin{array}{l}\text { PQ- } \\
93\end{array}$ \\
\hline Ames Mutagenicity & & $\mathrm{NM}$ & $\mathrm{NM}$ & $\mathrm{NM}$ & $\mathrm{NM}$ & $\mathrm{NM}$ & $\mathrm{NM}$ & $\mathrm{NM}$ & $\mathrm{NM}$ & $\mathrm{NM}$ & $\mathrm{NM}$ \\
\hline $\begin{array}{l}\text { NTP Carcinogenicity Call } \\
\text { (Male Rat) }\end{array}$ & $\mathrm{NC}$ & $\mathrm{NC}$ & $\mathrm{NC}$ & $\mathrm{NC}$ & $\mathrm{NC}$ & $\mathrm{NC}$ & $\mathrm{NC}$ & $\mathrm{NC}$ & $\mathrm{NC}$ & $\mathrm{NC}$ \\
\hline $\begin{array}{l}\text { NTP Carcinogenicity Call } \\
\text { (Female Rat) }\end{array}$ & $\mathrm{NC}$ & $\mathrm{NC}$ & $\mathrm{NC}$ & $\mathrm{NC}$ & $\mathrm{NC}$ & $\mathrm{NC}$ & $\mathrm{NC}$ & $\mathrm{NC}$ & $\mathrm{NC}$ & $\mathrm{NC}$ \\
\hline $\begin{array}{l}\text { NTP Carcinogenicity Call } \\
\text { (Male Mouse) }\end{array}$ & $\mathrm{NC}$ & $\mathrm{NC}$ & $\mathrm{NC}$ & $\mathrm{NC}$ & $\mathrm{NC}$ & $\mathrm{NC}$ & $\mathrm{NC}$ & $\mathrm{NC}$ & $\mathrm{NC}$ & $\mathrm{NC}$ \\
\hline $\begin{array}{l}\text { NTP Carcinogenicity Call } \\
\text { (Female Mouse) }\end{array}$ & $\mathrm{NC}$ & $\mathrm{NC}$ & $\mathrm{NC}$ & $\mathrm{NC}$ & $\mathrm{NC}$ & $\mathrm{NC}$ & $\mathrm{NC}$ & $\mathrm{NC}$ & $\mathrm{NC}$ & $\mathrm{NC}$ \\
\hline $\begin{array}{l}\text { Developmental Toxicity } \\
\text { Potential }\end{array}$ & $\mathrm{No}$ & $\mathrm{No}$ & $\mathrm{No}$ & $\mathrm{No}$ & $\mathrm{No}$ & $\mathrm{No}$ & $\mathrm{No}$ & $\mathrm{No}$ & $\mathrm{No}$ & No \\
\hline
\end{tabular}


RASĀYAN J. Chem.

Vol. 14 | No. 4 |2627-2638| October- December | 2021

\begin{tabular}{l|l|l|l|l|l|l|l|l|l|l}
\hline Rat Oral LD50 & 2.4 & 3.2 & 4.8 & 5.1 & 6.2 & 2.8 & 6.2 & 9.1 & 8.7 & 7.5 \\
\hline $\begin{array}{l}\text { Rat Maximum Tolerated Dose } \\
\text { - Feed/Water (v6.1) (mg/kg) }\end{array}$ & 81.2 & 88.3 & 68.1 & 78.2 & 89.2 & 96.1 & 92.1 & 88.4 & 83.1 & 81.2 \\
\hline $\begin{array}{l}\text { Rat Inhalational LC50 (v6.1) } \\
\text { (g/m3/H) }\end{array}$ & 36.2 & 25.1 & 75.1 & 48.1 & 86.1 & 42.6 & 86.7 & 88.3 & 24.7 & 18.3 \\
\hline Skin Irritation & NSI & NSI & NSI & NSI & NSI & NSI & NSI & NSI & NSI & NSI \\
\hline Skin Sensitization & NS & NS & NS & NS & NS & NS & NS & NS & NS & NS \\
\hline Ocular Irritancy & NOC & NOC & NOC & NOC & NOC & NOC & NOC & NOC & NOC & NOC \\
\hline Aerobic Biodegradability & BD & BD & BD & BD & BD & BD & BD & BD & BD & BD \\
\hline Fathead Minnow LC50 ug/l) & 85.4 & 77.2 & 69.4 & 86.4 & 77.2 & 47.5 & 93.8 & 48.2 & 56.8 & 25.8 \\
\hline Daphnia EC50 (mg/l) & 1.25 & 1.57 & 1.59 & 1.68 & 1.78 & 1.67 & 1.82 & 1.46 & 1.48 & 1.27 \\
\hline
\end{tabular}

$\mathrm{LD}_{50}$ - Lethal dose 50\%, LOAEL- lowest adverse effect level, TD 50 - Tumorigenic dose 50\%. FRC- Female rate carcinogenicity, FMC- Male rate carcinogenicity, C- Carcinogenicity, NC- Non-carcinogenicity, FMC- Female mouse carcinogenicity, MMC- Male mouse carcinogenicity, MU- Ames mutagenicity, NM- Non-mutagenicity, DTP -Development toxicity potential, T- Toxicity, SISkin irritation, NSI-Non skin irritation, SS- Skin sensitization, NS- Non-skin sensitization, I- Intermediate, OC-Ocular irritancy, NOC- Nonocular irritancy, BD- Aerobic biodegradable

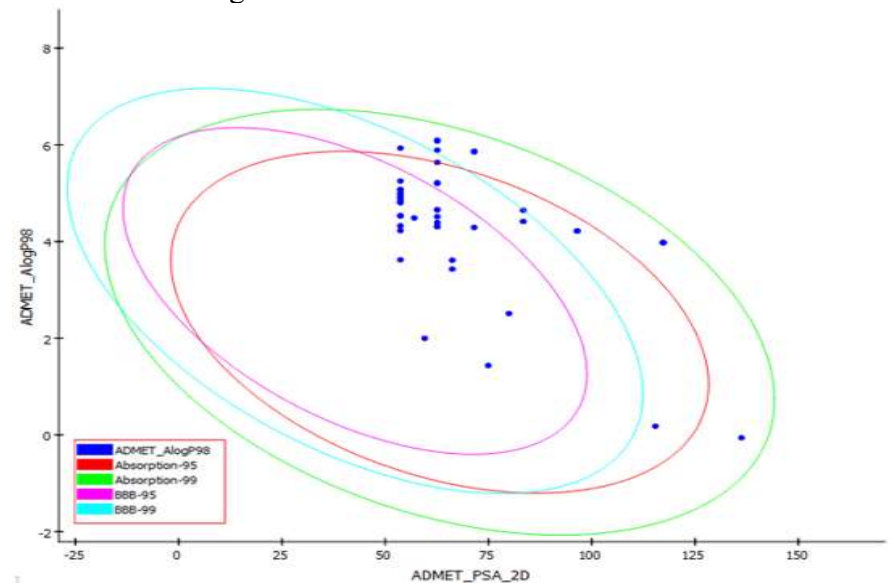

Fig.-15: Plot of PSA versus LogP for selected fifty PQ derivatives shown the $95 \%$ and $99 \%$ confidence limit ellipses corresponding to the blood-brain barrier (BBB) and human intestinal absorption (HIA) models

Table-3: Molecular Structure and Properties of Screened ten PQ-derivatives

\begin{tabular}{c|c|c|c|c}
\hline $\begin{array}{c}\text { Mol. } \\
\text { Name }\end{array}$ & IUPAC Name & Mol. Formula & $\begin{array}{c}\text { Mol. } \\
\text { Weight }\end{array}$ \\
\hline Molecular Structure & $\begin{array}{c}\text { 2-(3-bromophenyl)-3-\{4-[(6- } \\
\text { methoxyquinolin-8- } \\
\text { yl)amino]pentyl }\}-1,3- \\
\text { thiazolidin-4-one }\end{array}$ & $\mathrm{C}_{24} \mathrm{H}_{26} \mathrm{BrN}_{3} \mathrm{O}_{2} \mathrm{~S}$ & 500.46 \\
\hline
\end{tabular}


RASĀYAN J. Chem.

Vol. 14 | No. 4 |2627-2638| October-December | 2021

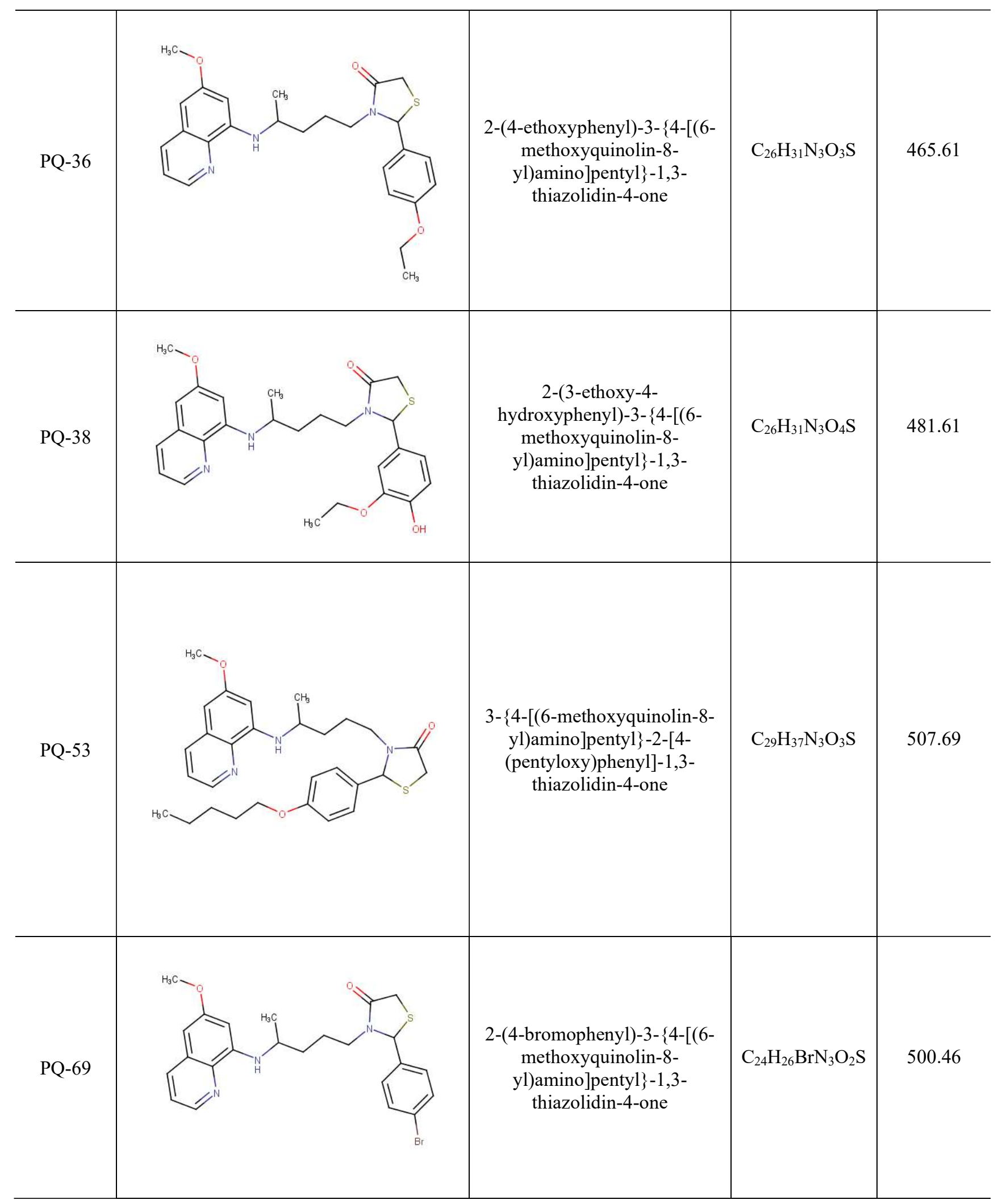


RASĀYAN J. Chem.

Vol. 14 | No. 4 |2627-2638| October-December | 2021

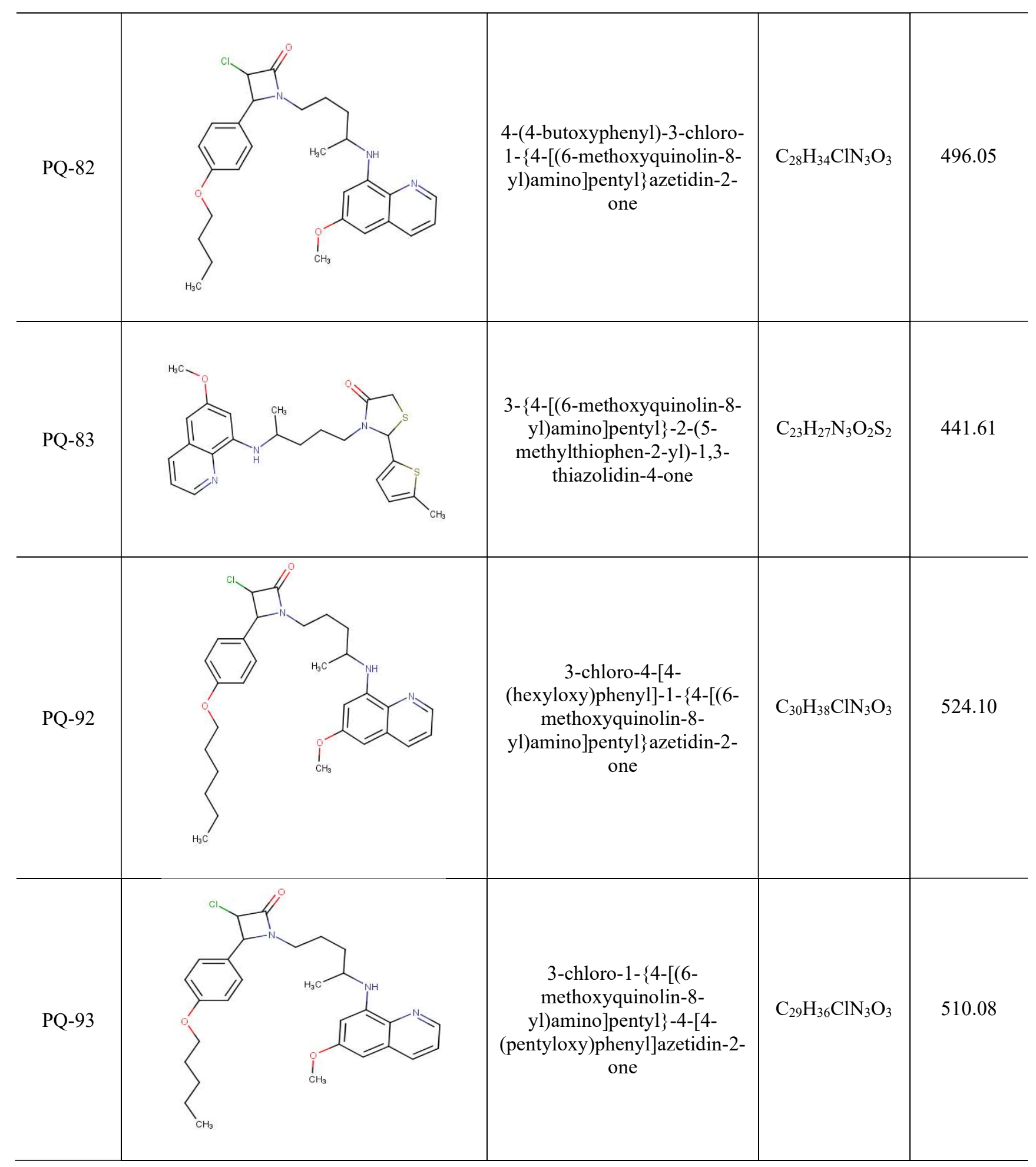

CONCLUSION

In this study, 100 novel PQ- derivatives were designed based on the synthetic possibility against MRSA, MDR-TB and R-E. coli. These bacterial strains are currently resisted by most antibacterial drugs in India. Since molecular docking studies were performed on MRSA, MDR-TB and R-E. coli receptors to find out the binding interactions of designed 100 novel PQ-derivatives. Based on the binding energy, only 50 PQ- 


\section{RASĀYAN J. Chem.}

Vol. 14 | No. 4 |2627-2638| October- December | 2021

derivatives were screened for further in silico ADMET and Toxicity parameters predictions. Based on these results, finally, PQ-13, PQ-24, PQ-36, PQ-38, PQ-53, PQ-69, PQ-82, PQ-85, PQ-92, PQ-93 derivatives were identified as a potential drug for MRSA, MDR-TB and R-E. coli. These ten molecules have good binding interaction with the active site MRSA, MDR-TB and R-E. coli receptors. Also, it does not show any toxic nature and shows good drug-likeness properties. Overall, the results of this study show that the ten compounds that were virtually screened can be employed to successfully combat MRSA, MDR-TB and R-E. coli pathogens.

\section{ACKNOWLEDGEMENT}

The authors gratefully acknowledge the Department of chemistry, Dr. Ambedkar Govt Arts College, Vyasarpadi for their constant support during this research work.

\section{REFERENCES}

1. F. Prestinaci, P. Pezzotti, A. Pantosti, Pathogens and Global Health, 109(7), 309(2015), https://doi.org/10.1179/2047773215Y.0000000030

2. N. Friedman, E. Temkin, Y. Carmeli, Clinical Microbiology and Infection, 22(5), 403(2016), https://doi.org/10.1016/j.cmi.2015.12.002

3. World Health Organization (WHO), Global Action Plan on AMR: 2017.

4. National Action Planon Antimicrobial Resistance (NAP-AMR)(2019).

5. E. Smith, C. Lichten, J. Taylor, C. MacLure, L. Lepetit, E. Harte, European Commission, Brussels, 2016.

6. Department of Health, Department for Environment Food and Rural Affairs, UK Five Year Antimicrobial Resistance Strategy, 2013 to 2018.

7. Government of India, National Action Plan on Antimicrobial Resistance (NAP-AMR),2017-2021.

8. R. Dahal, A. Upadhyay, B. Ewald. Veterinary Record, 181(23), 626(2017), https://doi.org/10.1136/vr.104189

9. World Health Organization (WHO), Regional Office for South-East Asia, Situational Analysis on Antimicrobial Resistance in the South-East Asia Region, Report, 2016.

10. A. Singer, H. Shaw, V. Rhodes, A. Hart, Frontiers in Microbiology, 7,1728(2016), https://doi.org/10.3389/fmicb.2016.01728

11. S. Balasubramaniyan, N. Irfan, A. Umamaheswari, A. Puratchikody, RSC Advances, 8(42), 23629(2018), https://doi.org/10.1039/C8RA01854E

12. A. Puratchikody, N. Irfan, S. Balasubramaniyan, Biocatalysis and Agricultural Biotechnology, 17, 427(2019), https://doi.org/10.1016/j.bcab.2018.12.014

13. R. Kharwar, R. B. Dixit, Rasayan Journal of Chemistry, 14(1),493(2021), https://doi.org/10.31788/RJC.2021.1415922

14. I. Irfan, M. Irfan, M. Abid, A. Azam, Rasayan Journal of Chemistry, 12(4), 2082(2019), https://doi.org/10.31788/RJC.2019.1245320

15. B.T. Purwanto, Siswandono, D. Kesuma, T. Widiandani, I. Siswanto, Rasayan Journal of Chemistry, 14(2), 1341(2021), https://doi.org/10.31788/RJC.2021.1426196

16. S. Murthy, T. Bala Narsaiah, Rasayan Journal of Chemistry, 12(4), 2030(2019), https://doi.org/10.31788/RJC.2019.1245475

17. C. Isaac, R. Narayanaswamy, K. Vallivitan, Rasayan Journal of Chemistry, 14(1), 659(2021), https://doi.org/10.31788/RJC.2021.1416107

[RJC-6516/2021] 